\title{
Solar-Wind Generated Roof Ventilation System (SiVATAS) for a Warm-Humid Climate
}

\section{Prasasto Satwiko}

To cite this article: Prasasto Satwiko (2004) Solar-Wind Generated Roof Ventilation System (SiVATAS) for a Warm-Humid Climate, International Journal of Ventilation, 3:3, 209-218, DOI: 10.1080/14733315.2004.11683915

To link to this article: https://doi.org/10.1080/14733315.2004.11683915

曲 Published online: 29 Mar 2016.

Submit your article to this journal $₫$

山 Article views: 6

Q View related articles ๘ 


\title{
Solar-Wind Generated Roof Ventilation System (SiVATAS) for a Warm-Humid Climate
}

\author{
Prasasto Satwiko \\ School of Architecture, University of Atma Jaya Yogyakarta, \\ Jl. Babarsari 44 Yogyakarta 55281, Indonesia
}

\begin{abstract}
This research grows out of a desire to find a Solar-Wind Generated Roof Ventilation System for low-cost dwellings located in high building density urban areas where horizontal air movement is restricted. A general purpose computational fluid dynamics (CFD-ACE+) program was utilised to explore, analyse and develop a roof model based on its aerodynamics and thermal performance to obtain optimum wind pressure and temperature differences. Comparisons were made with physical scale models. The research found that a roof prototype with inclinations of $15^{\circ}$ and $45^{\circ}$, curved ridge with cap, integrated roof chimney, black-matte steel sheet cover, combined with a perforated under floor channel (floor tunnel), can generate evenly distributed vertical cross ventilation within the occupant's zone. The created indoor air velocity was in the range of 0.15 to $0.7 \mathrm{~m} / \mathrm{s}$, which is considered to be sufficient to produce a physiological cooling effect. As an addition, the CFD program has proved to be a reliable, user-friendly and helpful research tool.
\end{abstract}

Key words: natural ventilation, solar chimney, CFD modelling, physiological cooling, humid climate, physical model, roof configuration, indoor air velocity, physical scale models.

\section{Introduction}

Architects have long considered designing passive ventilation for a warm-humid climate as a very difficult task. The main problem is the combination of high air temperatures $\left(26-32^{\circ} \mathrm{C}\right)$, high air relative humidity (60-90\%), and low air movement, which results in the indoor atmospheric conditions being outside the comfort zone for most of the time. An air conditioner seems to be the most practical solution, since it not only lowers the air temperature and humidity (which is almost impossible without mechanical intervention) but also eliminates other problems at the same time (e.g dust, outdoor noise, and insects).

Though their efficiency is improving, air conditioners still consume a significant amount of electrical energy. In Indonesia, for example, the smallest available air conditioner requires approximately 400 watts $(0.5 \mathrm{hp})$. It is still a luxury for most people considering that there are many houses with only 450 watts of electrical capacity. Thus, the development of a passive ventilation system is still relevant.

For a warm-humid climate passive ventilation systems, designed to increase the indoor air velocity, provide the only chance to obtain thermal comfort through the physiological cooling effect. Unfortunately, the wind velocity is usually insufficient to induce indoor air movement for such cooling. Meanwhile, this region receives abundant solar radiation ranging from less than 100 to slightly more than 1000 watts $/ \mathrm{m}^{2}$ almost every day.

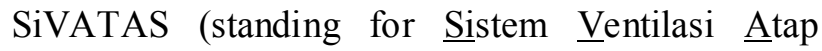
Tenaga Angin dan Surya or, in English, Solar-Wind Generated Roof Ventilation System) was developed as a technique to improve indoor air velocity. It utilizes the available solar radiation and wind to maximize air temperature and wind pressure differences, respectively. A simple residential building type T21 $\left(3 \times 7 \mathrm{~m}^{2}\right)$ (Figure 1) located in a high building density area was taken as the case study.

This paper reports the whole research process in developing SiVATAS. It begins with a discussion on the theoretical approaches of SiVATAS, and is followed by detailed descriptions of the model, the procedure, and the results underlining the research findings.

This research was conducted at the Hydraulics and Hydrology Laboratory, Inter-University Center for 
Engineering Sciences of Gadjah Mada University. It was chosen for its hardware and software availability. Moreover, this laboratory provides experts in the fields of fluid dynamics and heat transfer, which are the bases of this project.

The SiVATAS research project adopted a computer simulation method by using CFD-ACE + version 6.2 .3 (2004) as the main tool. The application of a CFD program, which is becoming a popular technique, assisted in developing the method in an efficient and inexpensive way.

\section{The Problem}

The problem of the research is to find a roof prototype design (SiVATAS), which can improve indoor ventilation by utilizing the low urban wind speed and abundant solar radiation of a warm-humid climate.

\section{The Potential Benefits of the Research}

\subsection{For People in General}

The SiVATAS is aimed at providing an inexpensive, and easy to build way of helping people living in high building density areas (such as in down town) to accomplish a comfortable and healthy indoor air movement. Its construction will also create many job opportunities.

\subsection{For Research Institution}

Presently, simulations using sophisticated computational fluid dynamics (CFD) programs are becoming more popular. The fertility of CFD programs, combined with relatively low computer prices, has made virtual laboratories more attractive than conventional (physical) ones. This is especially true for developing countries, such as Indonesia, where setting up a good conventional laboratory is usually unaffordable. Mastering a general-purpose CFD program will give research institutions, with limited resources, the ability to conduct various experiments with the same tool.

\subsection{For Building Science and Architecture}

This research will contribute to the development of building science for warm-humid climates, especially through research using sophisticated computer programs. From the architectural point of view, it is hoped that the result of this research will revolutionize warm-humid architecture towards more environmentally friendly architecture.

\subsection{For the Environment}

The intention of SiVATAS is to work totally with free renewable energy (wind and solar radiation) and is thus non-polluting and hence will assist in conserving the environment.

\section{The Method}

This research used computer simulation techniques to calculate and analyze the aerodynamic and thermal performances of SiVATAS. This included the aerodynamics and thermal consequences for any changes in its form and material.

\subsection{Procedure}

The procedure included:

- A Literature Study: A study of the available literature was made to find theories on how to effectively increase and transform, respectively, the air velocity on roof surfaces and the solar radiation into heat.

- Compilation of Climatic Data: climatic data for warm-humid regions and, in particular, Jogjakarta Special Region were collected from secondary and primary data bases (recorded by the Meteorology and Geophysics Agency).

- Compilation of Ideas; pencil sketched initial SiVATAS models were developed based on aerodynamic theories, thermal theories and climatic data.

- Preparation: initial pencil sketched SiVATAS models were transformed into digital formats using the pre-processor module of the CFD program. Each model was put in a virtual wind tunnel, which was constructed using the CFD program.

- Software Calibration: though much research has reported the accuracy of CFD programs, a small experiment was conducted to adjust the position of the virtual wind tunnel's inlet and outlet.

- Experiments on aerodynamics and thermal performance: Simulations and experiments were performed on how to use solar energy and any available wind to increase the air flow through the building.

- Verification of the prototype: At this stage, a physical model of SiVATAS was built based on the design found by computer simulation. This was to see whether the digital simulations agreed with real conditions. 


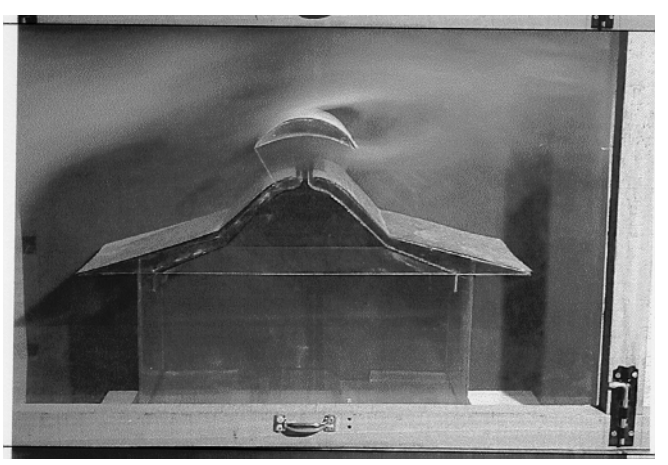

Figure 1. 1:12 scaled model of SiVATAS.

\subsection{Analysis Method}

The analysis method involved:

- Graphical analysis of CFD simulation results: The post-processor module of the CFD program was used to transform the numerical data into easy-to-read graphical presentations. The graphics clearly showed the distribution of air temperature, velocity, and flow pattern.

- Comparison with other research results: comparison with other research results was used when calibrating the software. This included comparisons with wind tunnel and other CFD experiments.

\subsection{Modelling}

This research was based on both computer and physical modelling in which computer models were used to simulate the aerodynamics and thermal properties and physical modelling was used to verify whether the results of computer simulations were applicable to real conditions.

Computer Modelling: Computer modelling followed three stages i.e: pre-processing (preparing computer model), calculation (simulate the models' aerodynamic and thermal performances), and postprocessing (presenting the results graphically).

Physical Modelling: Two physical models were built. The first was at half-scale and represented a slice of roof, cut in half widthwise and one metre longitudinally (see Figure 2). The roof cover was of a black-matte steel sheet to maximize solar radiation absorption. Its ceiling was constructed from aluminium foil and timber, as heat isolators, to prevent the heat from penetrating into the room beneath. This model was exposed to the sun and the interior air movement was observed. The second physical model was at 1:12 scale and located in a

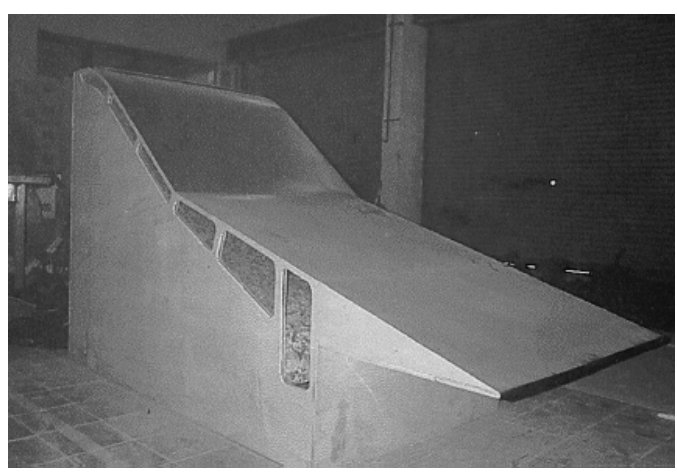

Figure 2. 1:2 scale model of SiVATAS.

box equipped with six fans at the outlet end to suck the air out See Figure 1. A smoke generator was positioned at the inlet end. This approach was used to observe the airflow pattern inside and outside the model.

\section{Theoretical Approach}

The initial research approach was based on climate conditions of very low wind speed and abundant solar radiation. Hitherto, the absence of sufficient wind has resulted in indoor air being at rest. Under these circumstances architectural practice considers solar radiation as an annoying heat source, which should be blocked outside by roofs and overhangs. However, the approach adopted in this project has been to utilise this free form of solar energy to generate indoor air movement. This is especially important for present day buildings because traditional methods, which are based on maximising openable area, are not always suitable for security, privacy and cleanliness reasons. Also, new buildings tend to have more complicated room divisions compared to the single room traditional buildings. Complicated room design means that air cannot flow freely inside the room. Thus, it makes physiological cooling more difficult to achieve.

There are two ways to induce more air movement, i.e. by creating higher wind pressure difference and higher air temperature difference. The former can be approached by adopting the Bernoulli and Venturi effects. Bernoulli's principle states that in fluid flow, an increase in velocity happens simultaneously with decrease in pressure. Venturi's effect is the phenomenon which exists in a Venturi tube, where fluid tends to speed up when it flows through a cone shape tunnel; then it generates Bernoulli's effect. 


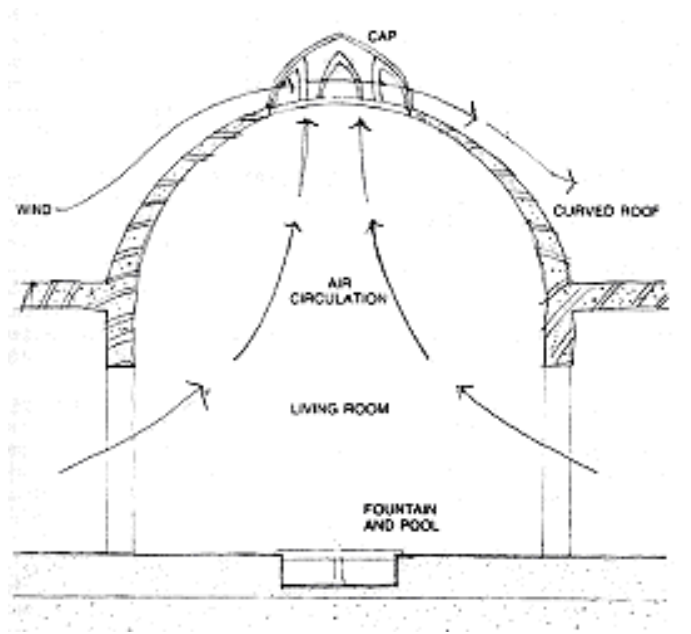

Figure 3. Iran dome (Bahadori, 1978).

\subsection{Maximizing Pressure Difference}

To maximize air pressure difference, SiVATAS was designed in such a way as to induce both the Bernoulli and Venturi effects. Learning from traditional Iranian dome architecture (Bahadori, 1978), illustrated in Figure 3, and by applying computer simulations, it was found that a curved ridge created the fastest air velocity and greatest negative pressure. Placing an object, a cap, above and close to this ridge created the Venturi effect, which further increased the air velocity (see Figure 7) by further adding to the negative pressure. When a narrow linear air gap was made at the apex of the ridge, the air pressure difference between the indoor air and the negative pressure at the ridge created strong air suction. This draws indoor air out and induces vertical ventilation. The distance between the cap and the ridge must be slightly greater than the width of the ridge air gap, otherwise the opposite mechanism will occur in which air will be pushed down into the room through the gap.

\subsection{Maximizing Temperature Difference}

Using the stack effect to generate vertical ventilation is not a new idea for example, Stulz (2000). Baker (1984), Barrozi (1992) and Satwiko (1994) are some of the researchers who applied this approach. Their designs are illustrated in Figures 4 to 6 . The stack effect is influenced by the air temperature difference and the vertical distance (height) between the lower and upper openings. To maximize the air temperature difference, black-matte steel sheet was used for the outer skin of SiVATAS. Experiment found that, on bright sunny days of $27^{\circ} \mathrm{C}$ air temperature, a black-matte steel sheet placed normal to the sun reaches more than $80^{\circ} \mathrm{C}$. This is very much higher than a new reflective steel sheet, which only reaches $40^{\circ} \mathrm{C}$. The hot black-matte steel heats the air around it thus causing the air to become less dense and hence to rise.

The SiVATAS was designed as a double layer roof, which formed an integrated roof chimney. The outer layer, i.e. the black-matte steel sheet, absorbs solar radiation and increases in temperature. The lower layer, the ceiling, was constructed from aluminium foil and $4 \mathrm{~cm}$ thick timber to provide thermal insulation so that the heat from the chimney cannot leak to the room underneath it. The hot air inside

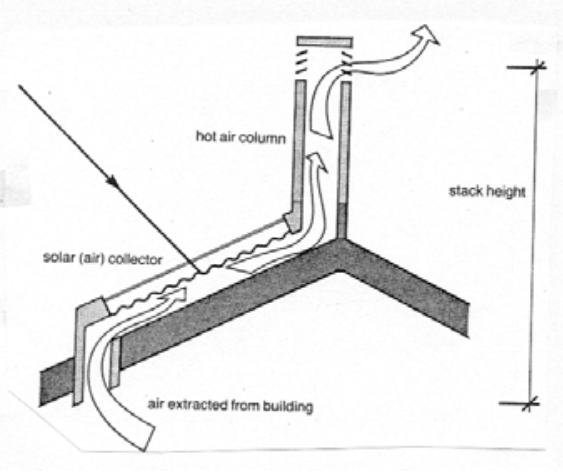

Figure 4. Solar chimney (Baker, 1984).

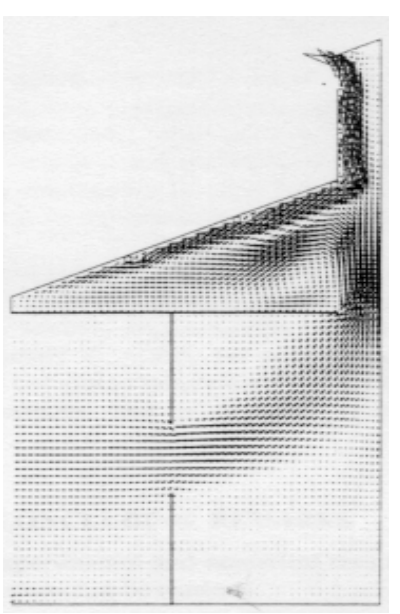

Figure 5. Solar chimney developed by Barozzi et al (1992).

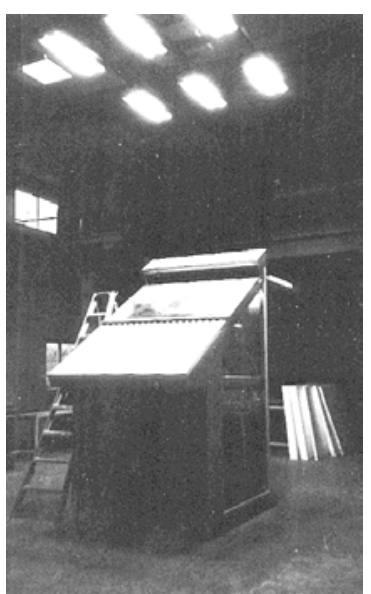

Figure 6. Solar chimney developed by Satwiko (1994). 
this integrated roof chimney rises by means of the stack effect (buoyancy) and is released via the upper opening. This mechanism induces vertical ventilation in the room below via the chimney.

\subsection{Refining the Model}

The initial SiVATAS model was modified to make it more practical. The first adjustment was to change the roof inclination from single $45^{\circ}$ to dual $15^{\circ}$ and $45^{\circ}$ inclinations. This minimised the unusable space below, thus maximising the living area. The second adjustment was to construct an elevated perforated floor (floor tunnel) inspired by Malaysian architecture. This perforated floor makes it possible to have room partitions without necessarily obstructing air movement, since the air can still freely move under and through the floor to create vertical ventilation. The third modification was to make the base of the model slightly wider than its wall. Preliminary experiments found that this method encourages outdoor air to enter the floor tunnel. This is particularly true for a building surrounded by a group of buildings since vortices occur within the intervening spaces.

\section{The Experiment}

\subsection{The Model}

The SiVATAS model was tested in a virtual (CFD) wind tunnel (representing 150 to $200 \mathrm{~m}$ in length and $60 \mathrm{~m}$ in height) in two versions: a single building and a group of buildings. In the former version, a building with SiVATAS was positioned $90 \mathrm{~m}$ from the inlet and $60 \mathrm{~m}$ from the outlet. In the latter, a group of buildings with SiVATAS was constructed. All the models were constructed using a combination of structured and unstructured grid systems.

The capability of available CFD programs in simulating aerodynamics and thermal performance have improved over time. Satwiko et al (1997), using real pressure coefficient data from the Texas Experimental Building, compared the result of simulations using a CFD 'virtual wind tunnel' program (Selvam, 1992) and a real wind tunnel. They found that CFD programs could reproduce results to a higher accuracy, when compared with the real building, than conventional wind tunnels. Another experiment by Satwiko confirms that the CFD program's ability to reproduce thermal phenomena is very good. He used Williams et al's (1996) and deVahl's (1983) experiments as the benchmarks.
Despite opinions that CFD is now a mature engineering design tool, its application to warmhumid ventilation computation, where natural ventilation is dominant, still needs to be developed further (Aynsley, 1999). In cases similar to SiVATAS research, CFD programs were used satisfactorily to simulate airflow in and around a glasshouse with ridge openings (Reichrath, 2001) and across the openings of a Thai Buddhist Temple (Sreshthaputra, 2002). The CFD predictions must be performed, however, with the application of suitable models for both turbulence and thermal radiation effects. In addition, the absorption characteristics of air, due to concentration of water vapour in the atmosphere, must be properly assessed and included as part of the simulation if a realistic prediction is to be generated (Howell, 2001).

\subsection{The Simulation}

The CFD program requires inputs representing problem type, flow domain (material, type of flow, etc.), boundary conditions (walls, inlet, outlet, symmetric wall), and calculation method. The problem type is used to activate calculation modules; in this case, Flow, Heat Transfer, and Turbulence modules. The flow domain was set as air (density: $1.177 \mathrm{~kg} / \mathrm{m}^{3}$, kinematic viscosity: $1.57 \mathrm{E}-005$, specific heat: $1005 \mathrm{~J} / \mathrm{kg} . \mathrm{K}$, conductivity: $0.026 \mathrm{~W} / \mathrm{m} . \mathrm{K}$, temperature: $27^{\circ} \mathrm{C}$, Prandtl number: 0.9 ). The flow is time independent (steady), subjected to gravity of $9.8 \mathrm{~m} / \mathrm{s}^{2}$, and is turbulent. Roughness Height (RH) of the ground was set to 0.03 .

Initial wind was defined at the inlet using an atmospheric boundary layer to obtain a realistic wind profile based on the exponent law (Aynsley, 1977; Etheridge, 1996). The wind speed at 10 metres above ground is $3.53 \mathrm{~m} / \mathrm{s}$ (Satwiko, 1999). The turbulent kinetic energy and energy dissipation rate were set to 0.33 and 0.48 respectively.

The calculation used the standard k-e turbulent model with 600 iterations. To avoid convergence problems, relaxation was applied. For Velocity, Pressure Correction and Turbulence, the relaxation parameters were set to 0.5 . For Pressure, Density and Viscosity, they were set to 0.7. The Temperature calculation was relaxed by 1 .

The SiVATAS model conditions were:

- Outer skin (roof cover) temperature: $80^{\circ} \mathrm{C}$

- Ceiling temperature: $27^{\circ} \mathrm{C}$

- Human body temperature: $37^{\circ} \mathrm{C}$

- Outdoor air: $27^{\circ} \mathrm{C}$ 


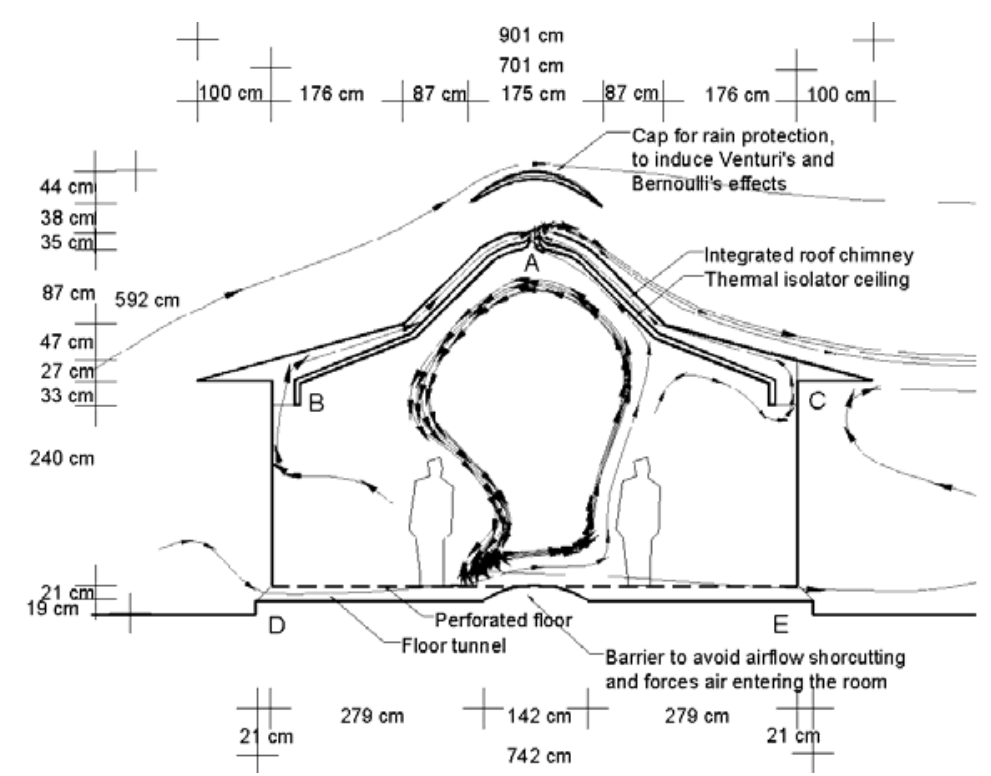

Figure 7a. Section of a house with SiVATAS and particle tracking by CFD-ACE+.

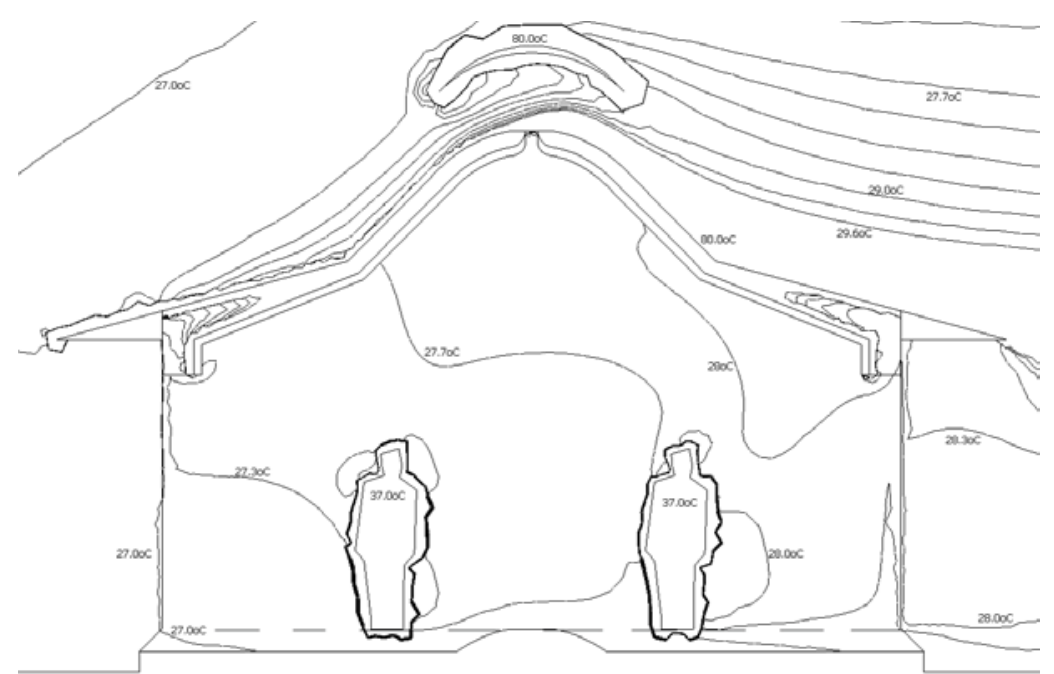

Figure 7b. Air temperature distribution by CFD-ACE+.

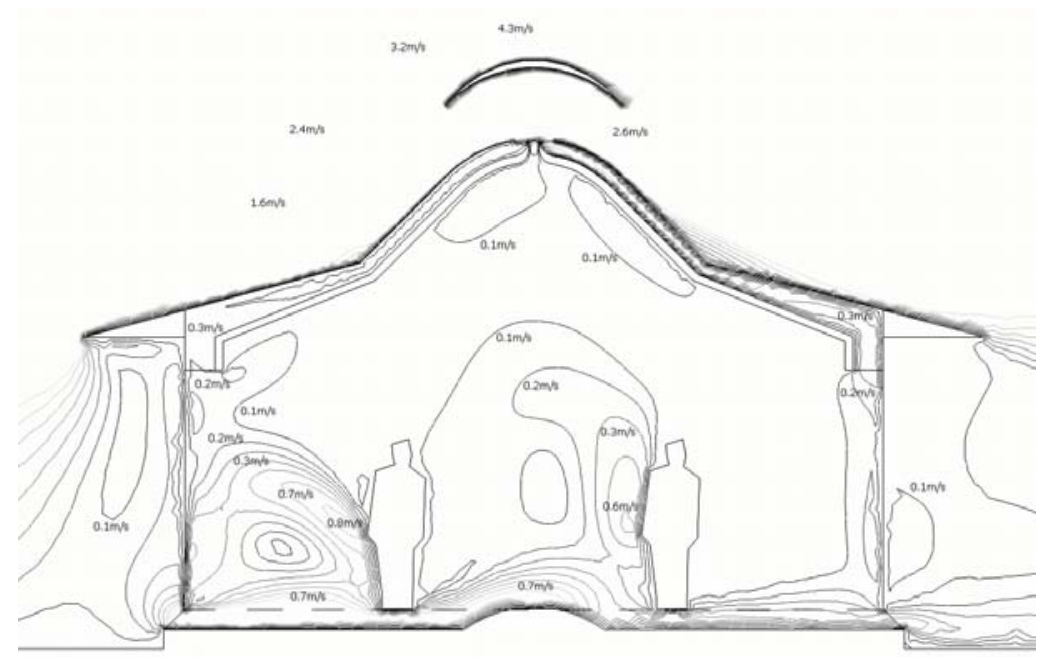

Figure 7c. Distribution of air speed by $C F D-A C E+$.

Figure 7. Single building simulations. 


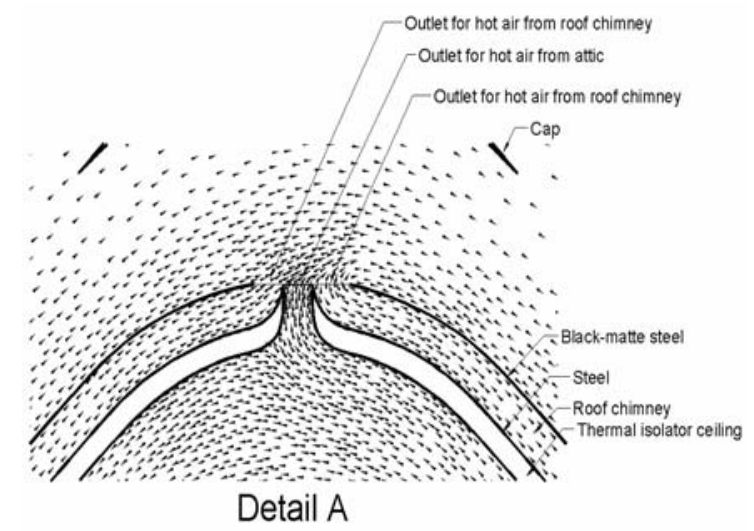

Figure 8a. Air outflow from roof chimney and top of room openings.

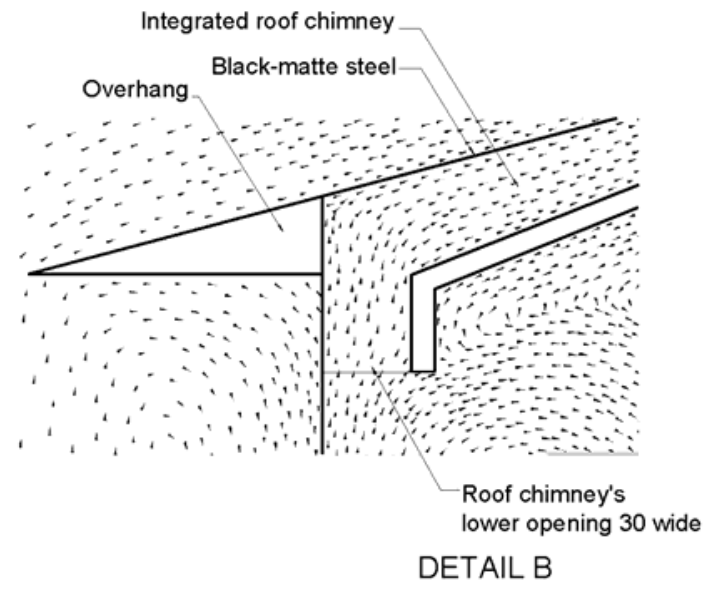

Figure 8b. Indoor air enters roof chimney's lower opening at detail $B$.

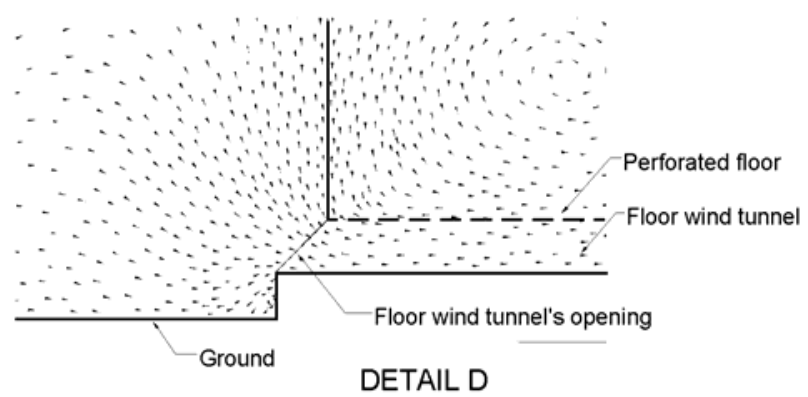

Figure 8d. Airflow pattern at detail D. Outdoor air enters the perforated under floor channel (floor tunnel).

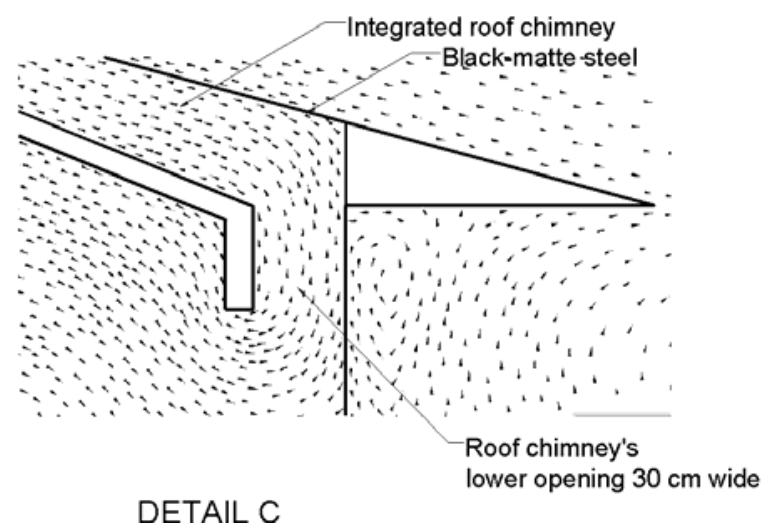

Figure 8c. Indoor air enters roof chimney's lower opening at detail $C$.

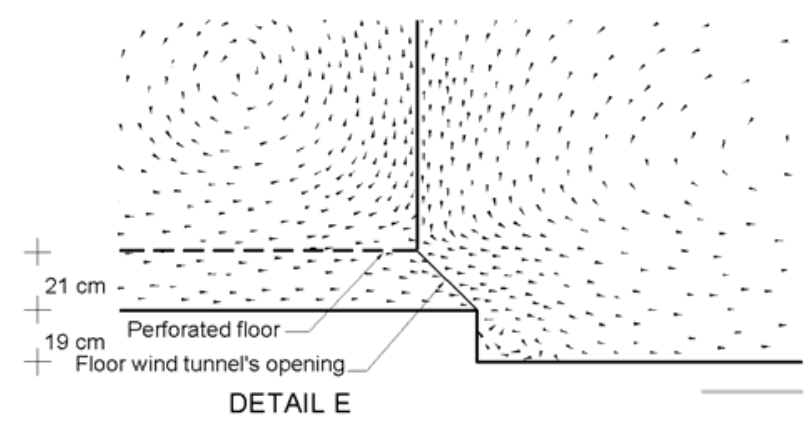

Figure 8e Airflow pattern at detail E. Indoor air can flow out from floor tunnel.

Figure 8. Air flows at detailed positions. 
The two-dimensional SiVATAS model contained 12,500 cells. For 300 iterations it took 18 minutes (using a Pentium III $500 \mathrm{~Hz}$ processor, $256 \mathrm{MB}$ RAM, and Windows 2000 OS). The threedimensional model consisted of approximately 200,000 cells and took 5 hours for 300 iterations.

\subsection{The Results}

Based on a wind speed of $3.53 \mathrm{~m} / \mathrm{s}$ at $10 \mathrm{~m}$ above the ground, the first stage experiment (aerodynamic experiment) found that a $45^{\circ}$ pitched roof with a quarter circle formed ridge (radius: $30 \mathrm{~cm}$ ) created an enhanced wind speed of $6.2 \mathrm{~m} / \mathrm{s}$ at the apex. This speed could be further increased, to $10.5 \mathrm{~m} / \mathrm{s}$, by placing a $1.75 \mathrm{~m}$ wide cap $0.82 \mathrm{~m}$ above the apex to create the Venturi effect. This means, according to Bernoulli's principle, that the apex will experience the greatest negative pressure. Considering that air velocity will increase along with increase in pressure difference, any opening at the apex has a high potential to draw the air out.

The second stage experiment (thermal experiment) found that the integrated roof chimney could produce a very good stack effect. It was proved that the stack effect was generated when the roof temperature rose. The lower openings of the roof chimney were lowered and were positioned slightly above the occupants' zone. This was to encourage horizontal airflow in the occupants' zone. The middle air gap, at the ridge, was needed to release hot air, which usually accumulates under the roof.

The third stage experiment was to elaborate and develop the SiVATAS design. At this stage some modifications were made including:

- Reducing the unusable space under the roof by dividing the roof into two parts with different inclination, i.e. $15^{\circ}$ for the lower part and $45^{\circ}$ for the upper part.

- Setting the position and the width of the cap above the ridge to obtain the largest Venturi effect, while still preventing the rain from entering the air gaps.

- Elevating the floor to improve the air speed entering the floor tunnel. Slightly widening the model base also enabled the inlet and outlet of the floor tunnel to face upward. This was proved more effective at entraining air into the occupied space.

- Placing a wind barrier at the centre of the floor tunnel to prevent short-circuiting from the inlet to outlet. This barrier forced air to enter the room.

Results of these simulations are illustrated in Figures 7, 8 and 9. Figure 7 shows simulation results for a single building and Figure 8 gives detailed flow patterns at specific parts of the roof and floor. Simulations for a group of houses are presented in Figure 9.

At this stage it was found that, with all windows closed, and applying the wind speed of $3.53 \mathrm{~m} / \mathrm{s}$ at $10 \mathrm{~m}$ above the ground, combined with solar radiation of $540 \mathrm{~W} / \mathrm{m}^{2}$, SiVATAS could generate an indoor air speed range from 0.15 to $0.7 \mathrm{~m} / \mathrm{s}$, which can induce physiological cooling. When the wind was calm $(0 \mathrm{~m} / \mathrm{s})$, the heat from absorbed solar radiation can create an indoor air velocity of $0.4 \mathrm{~m} / \mathrm{s}$.

Verification, using the physical model, found that SiVATAS can successfully create indoor air movement by drawing indoor air out from the roof level opening. The observed airflow patterns and velocity were not completely similar to those of the computer simulation. However, this is due to differences in scale and detail.

\section{Conclusions}

The research successfully found a roof design, which induced vertical cross ventilation in a closed building with the help of outdoor air movement and solar radiation. The design incorporates a combination of planar and curved form (to maximize the air velocity on the roof surface), integration of chimney into roof form (to avoid architectural destruction), the use of black-matte steel sheet as the roof material (as the heat collector), and floor ventilation (adopted from an elevated floor system). By applying this design it has been possible to create a solar induced uniform and even distribution of airflow in an indoor space (even when there is an internal wall). Computer simulation showed that the indoor air (which was expected to be warmer, more humid, and more polluted by indoor activities) was driven out through the chimney. It was replaced by outdoor air (which was expected to be cooler and fresher) through gaps in the floor. An experiment based on placing a building model in a building compound gave promising result. Although shading each other, every building (even without the use of openable windows) can still provide appropriate ventilation. 


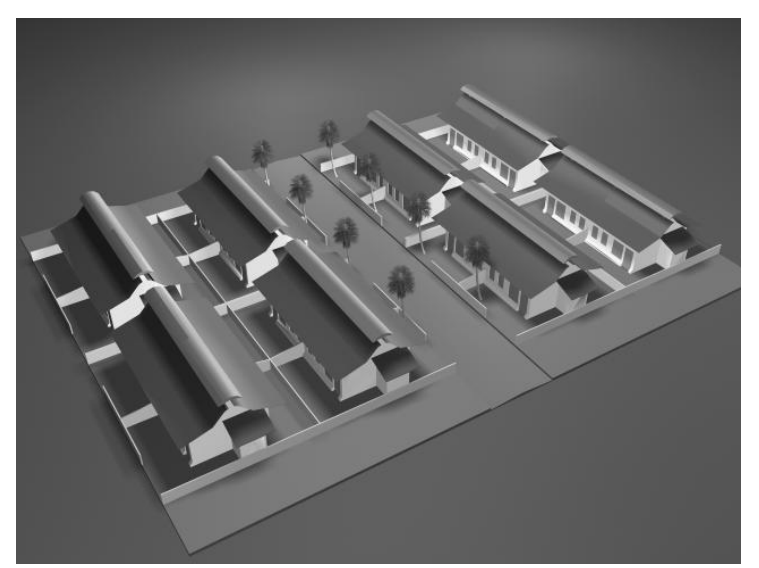

Figure 9a Model of housing applying SiVATAS.

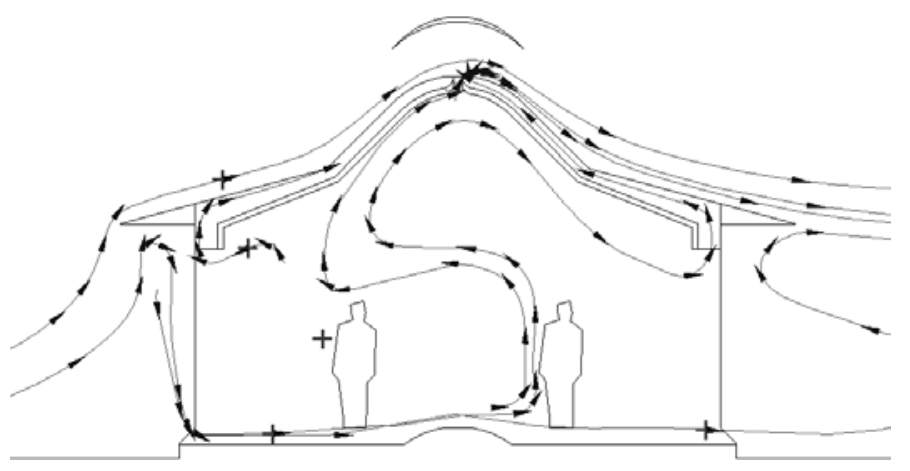

Figure $9 b$ Particle tracking using CFD-ACE+.

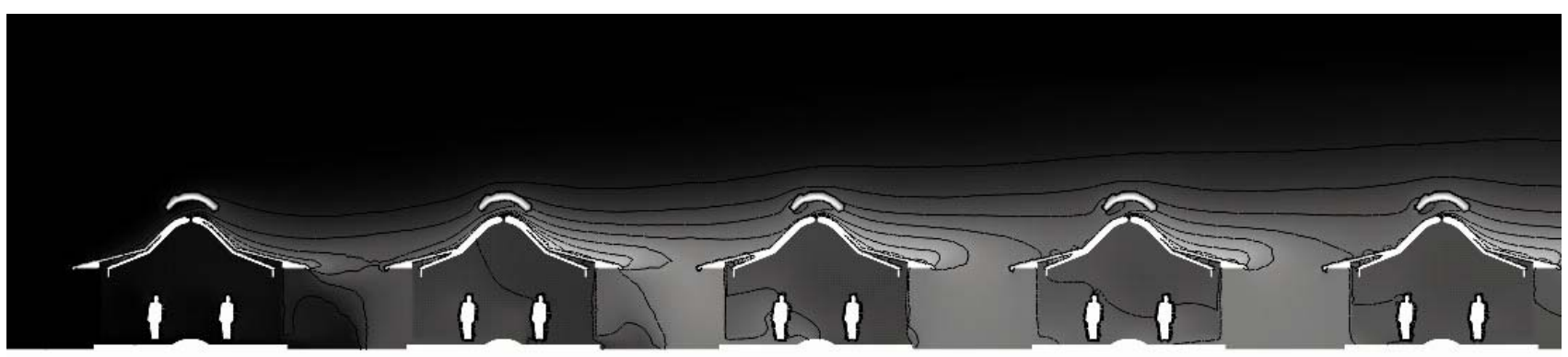

Figure 9c. Temperature distribution of a group of SiVATAS, simulated by CFD-ACE+. Temperature range is set from $27^{\circ} \mathrm{C}$ (darker) to $37^{\circ} \mathrm{C}$ (lighter). The actual temperature range is $27^{\circ} \mathrm{C}$ to $80^{\circ} \mathrm{C}$.

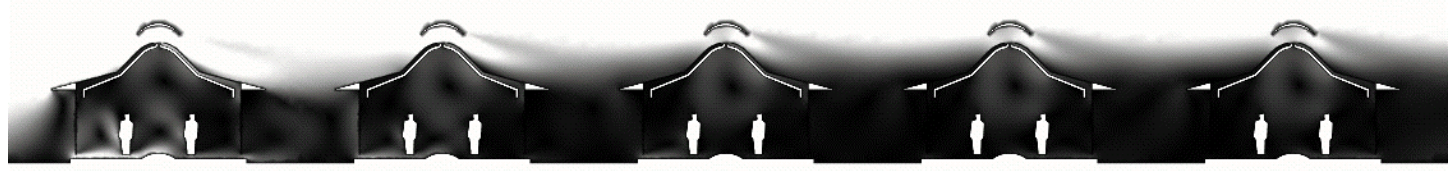

Figure 9d. Air velocity distribution in a group of SiVATAS simulated by CFD-ACE+. Velocity range is set from $0 \mathrm{~m} / \mathrm{s}$ (darker) to $1 \mathrm{~m} / \mathrm{s}$ (lighter). The actual velocity range in the flow domain is $0 \mathrm{~m} / \mathrm{s}$ to $10.5 \mathrm{~m} / \mathrm{s}$.

Figure 9. Simulations for housing model.

Also it should be noted that the temperature of the black-matte roof decreases immediately after sunset. Thus, at night, cooler air beneath the black-matte roof flows down and enters the room while the warmer, indoor air, escapes through the ridge opening.

In conclusion, the results of the research show SiVATAS to have the following benefits:

- Obtains thermal comfort through physiological cooling. Increasing air movement is the most logical way to passively achieve thermal comfort in a warm-humid climate. Other thermal comfort factors, i.e. air temperature and humidity, are very difficult to adjust without mechanical means.
- Saves energy by directly utilizing solar and wind energy. The depletion of fossil-based energy should encourage people to maximize sustainable free energy such as solar and wind energy.

- Since it uses renewable energy, SiVATAS is environment friendly.

- Uses no mechanical parts.

- Suitable for high building density areas, where horizontal air movements at normal opening height are obstructed by neighbouring buildings, or minimum openings are required (for privacy and security reasons).

- Can be integrated to various roof forms.

- No operational costs.

- Low maintenance costs. 


\section{Remark}

Even though SiVATAS has been proved to successfully generate reasonable vertical ventilation, it might increase environment temperature due to its hot surfaces. Further research is needed to check this.

\section{Acknowledgement}

The author would like to thank The Directorate General for Higher Education of Indonesia for financially supporting this research through the Domestic Collaborative Research Grant; The University of Atma Jaya Yogyakarta for giving unlimited access to the computer laboratory's facilities; The Hydraulics and Hydrology Laboratory, Inter-University Center for Engineering Sciences of Gadjah Mada University for providing the hardware and software; CFD Research Corporation of Huntsville, Alabama for providing academic license for the CFD program; and Mr. Soesilo Boedi Leksono as the co-researcher.

\section{References}

Aynsley RM, Melbourne W and Vickery BJ: (1977) "Architectural Aerodynamics", Applied Science Publisher Ltd, London.

Aynsley RM: (1999) "Unresolved Issues in Natural Ventilation for Thermal Comfort," Technical Paper Presented at the First International One day Forum on Natural and Hybrid Ventilation, HybVent Forum'99, 09/1999, Sydney, Australia.

Etheridge D and Sandberg M: (1996) "Building Ventilation: Theory and Measurement", John Wiley $\&$ Sons, Chichester.

Bahadori MN: (1978) "Passive Cooling System in Iranian Architecture", Scientific America, 238, (2), February, pp144-152.

Baker E, Floro CJ, Gostelow JP, McCaffrey: (1984) "Solar Heating and Cooling System, Design for Australian Conditions", Pergamon, Sidney, p.126.

Barozzi GS, Imbabi MSE, Nobile E and Sousa ACM: (1992) "Physical and Numerical Modeling of a Solar Chimney-based Ventilation System for Buildings", Building and Environment, 27, (4), pp433-445.
De Vahl DG: (1983) "Natural Convection of Air in a Square Cavity: a Benchmark Numerical Solution", Int. J. Numer. Meth. Fluids, 3, pp249-264.

Howell SA and Potts I: (2001) "On the Natural Displacement Ventilation Flow through a Full Scale Enclosure, Driven by a Source of Buoyancy at Floor Level", Proceedings of the Seventh International IBPSA Conference, August 13-15, Rio de Janeiro, Brazil.

Reichrath S and Davies TW: (2001) "Applications of Computational Fluid Dynamics in Glasshouse Research", Agribuilding 3-6 September, Campinas, SP, Brazil.

Satwiko P: (1994) "The Development and Modeling of a Natural Ventilation System for Indonesian Condition - Case study of a roof chimney", unpublished Master of Building Science thesis, School of Architecture, Victoria University of Wellington, New Zealand.

Satwiko P, Locke N and Donn M: (1997) "Reproducing the Real Pressure Coefficient Using a Computational Fluid Dynamic Program - How Close is Close Enough?, Proceedings of the $32^{\text {nd }}$ Annual Conference of the Australia and New Zealand Architectural Science Association, School of Architecture, Victoria University of Wellington, New Zealand.

Selvam RP: (1992) "Computation of Pressure on Texas Tech Building", Journal of Wind Engineering and Industrial Aerodynamics, 41-44 pp1619-1627.

Sreshthaputra A, Haberl J and Andrews MJ: (2002) "3-D Studies of Heat Transfer and Airflow in an Unconditioned Thai Buddhist Temple," Journal of Energy, Heat, and Mass Transfer, 23, pp455-471.

Stulz R: (2000) "Roofing Primer", Skat Foundation, Switzerland.

Williams PT, Baker AJ and Kelso RM: (1996) "Numerical Calculation of Room Air Motion - Part 2: The Continuity Constraint Finite Element Method for Three-Dimensional Incompressible Thermal Flows", ASHRAE Transactions, 100, part 1.

CFD-ACE+ version 6.2.3: (2004) "Advanced CFD \& multiphysics software for the simulation of fluid, thermal, chemical, biological, electrical and mechanical phenomena" ESI Group, www.cfdrc.com. 